\title{
Reported food intolerance and respiratory symptoms in young adults
}

\author{
R.K. Woods*+, M. Abramson ${ }^{\ddagger}$, J.M. Raven*, M. Bailey , J.M. Weiner+, E.H. Walters*+
}

Reported food intolerance and respiratory symptoms in young adults. R.K. Woods, M. Abramson, J.M. Raven, M. Bailey, J.M. Weiner, E.H. Walters. OERS Journals Ltd 1998. ABSTRACT: The aim of the study was to assess the ability of the European Community Respiratory Health Survey (ECRHS) questionnaire to provide data on the prevalence, type and reported symptoms associated with food intolerance from a group of young adults in Melbourne.

Six hundred and sixty nine randomly selected subjects completed the questionnaire with 553 attending the laboratory for skin-prick tests, anthropometry, and ventilatory function tests. A further 207 symptomatic participants completed the questionnaire, with 204 of them attending the laboratory.

Seventeen per cent of all respondents reported food intolerance or food allergy. A wide variety of food items was cited as being responsible for food-related illnesses. Those with current asthma did not report food-related illness more frequently than those without asthma. Respondents who reported respiratory symptoms following food ingestion were more likely to be atopic, to have used inhaled respiratory medications in the previous 12 months, reported less exposure to regular passive smoking over the past 12 months and weighed more.

These associations between respiratory symptoms and food intolerance require further prospective investigation and verification. The importance of using appropriate dietary methodology in future studies for determining diet-disease relationships was highlighted by this study.

Eur Respir J 1998: 11: 151-155.
Depts of *Respiratory Medicine, ology and Preventive Medicine and ${ }^{+}$Medicine, Monash Medical School and Alfred Hospital, Melbourne, Australia

Correspondence: R.K. Woods, Dept of Respiratory Medicine, Alfred Hospital, Commercial Road, Prahran, Victoria 3181, Australia. Fax: 0061392763434

Keywords: Atopy, dietary assessment, epidemiology, food intolerance, respiratory

Received: December 301996

Accepted after revision July 81997

This study was supported by Allen and Hanbury's, Australia. Kabi-Pharmacia, Sweden provided the Phazets ${ }^{\mathrm{TM}}$.

The results presented here are from a local analysis of data collected for the ECRHS Any final comparison may use a different analysis.
Asthma is a common source of morbidity and is a major public health problem in Australia. It has previously been shown that the prevalence of wheeze that limits speech, frequent nocturnal wheezing and doctor-diagnosed asthma are higher in Australasian children than in Europe [1]. Until recently there has been little published information comparing the prevalence of adult asthma between countries using standardized epidemiological methods. Analysis of the first phase of the European Community Respiratory Health Survey (ECRHS), which was conducted in over 50 countries worldwide between 1992 and 1994, showed that respiratory symptoms are more common in Australia, New Zealand, the west coast of the USA and the UK, than in continental Europe [2]. Indeed, more young adults from Melbourne, Australia reported an attack of asthma during the preceding 12 months than from any other centre [3]. The ECRHS was also concerned with risk factors that may explain the international variation in asthma prevalence.

The relationship between diet and asthma is an area of controversy that has never been fully evaluated [4]. Epidemiological studies have, to date, provided conflicting opinions with regard to diet as a risk factor for asthma. There have been reports that anti-oxidants, particularly vitamin $\mathrm{C}$, magnesium, selenium and fish oils may be protective factors for asthma [5-8]. Dietary sodium has been implicated in the aetiology of bronchial hyperresponsive- ness and asthma [9]. However, further well-conducted observational studies and controlled clinical trials are required before any conclusions can be drawn.

A large proportion of people with asthma perceive that diet plays an important part in their asthma control. In a recent survey of 135 Melbourne adults with asthma who had attended an asthma and allergy clinic, $73 \%$ reported food-induced asthma [10]. Furthermore, $61 \%$ stated that they had tried to modify their diet in order to improve their asthma control. By far the majority of dietary modifications were dietary restrictions. Other dietary perception studies, both in adults and children, have reported similar findings [11-13].

Double-blind, placebo-controlled food challenges are the "gold standard" for the diagnosis of adverse reactions to foods and food additives [14] and have shown that fewer than $5 \%$ of patients may have objective evidence of food-induced asthma $[15,16]$.

There are no published studies that have gathered data contemporaneously from the community on people with and without asthma in order to determine whether dietary manipulation is unique to those with asthma or whether it merely reflects general community concern and behaviour in regard to diet and health. The aim of the present study was to assess the ability of the ECRHS questionnaire to provide data on the prevalence, type and reported symptoms associated with food ingestion among young adults 
in the Melbourne community. We also aimed to identify characteristics of those who reported food-related respiratory symptoms.

\section{Materials and methods}

\section{Study subjects}

The subjects were participants in the second phase of the ECRHS in Melbourne. The full details of the sampling protocol have been described elsewhere [2, 17]. Briefly, 4,500 adults aged 20-44 yrs were randomly selected from the electoral roll. Postal questionnaires were returned by $3,200(72 \%)$ of subjects in the first phase of the ECRHS. Random and symptomatic samples were invited to the laboratory for the second phase of the study. From the random sample, 669 participants completed the questionnaire with 553 attending the laboratory for further testing. An additional 207 symptomatic participants completed the questionnaire with 204 of these attending the laboratory for further testing. Thus, a total of 757 participants completed the questionnaire in the laboratory with a further 119 by telephone interview.

\section{Questionnaire}

Participants completed the detailed second phase ECRHS questionnaire administered by one of three trained interviewers. The background and validity of this questionnaire have been described elsewhere [2]. Briefly, the questionnaire covered: respiratory symptoms (including wheeze, shortness of breath, cough and phlegm production) during the previous 12 months; history of asthma; home and work environment; allergic symptoms; smoking; demographic information; medications: and dietary information.

There were only four questions relating to diet. The aim of the first three questions was to gather information on the amount of convenience food and "junk" food that the respondents were consuming, from which to gain an indication of sodium and food additive intake. However, it was not possible to calculate food additive and sodium intakes from the data collected and, therefore, these responses will not be considered further in this analysis. The fourth question asked whether respondents had ever suffered any "illness/trouble" from food ingestion, and if so to list the food(s) and the symptoms in order to distinguish between symptoms of indigestion/food poisoning and food allergy or intolerance.

\section{Ventilatory function testing}

Spirometry was measured according to the American Thoracic Society (ATS) criteria using a computerized Fleisch number 3 pneumotachograph connected to a Hewlett Packard, Lung Function Analyser (Lexington, MA, USA) [18]. The initial forced expiratory volume in one second (FEV1) was recorded as the best of five expiratory manoeuvres. Methacholine (Provocholine ${ }^{\mathrm{TM}}$; Hoffman La Roche, Basel, Switzerland) was delivered via a Mefar 3B dosimeter (Mefar srl, Bovezzi, Italy) until the FEV1 fell by $20 \%$ from the initial value or until a cumulative dose of $2 \mathrm{mg}(10 \mu \mathrm{mol})$ had been administered. The details of the measurement of spirometry and methacholine challenge testing have been reported elsewhere [2, 17]. Bronchial hyperreactivity (BHR) was defined as a provocative dose of methacholine causing a 20\% fall in FEV1 (PD20) $<2$ mg. Current asthma was defined as the combination of wheezing in the last 12 months and BHR [19].

\section{Skin-prick testing}

The details of skin-prick testing with 11 common aeroallergens have been reported elsewhere [17]. Atopy was defined as a positive reaction (a wheal $\geq 3 \mathrm{~mm}$ diameter) to any allergen, in the context of a positive histamine control and negative reaction to the uncoated lancet.

\section{Statistical analysis}

Data from the questionnaires, ventilatory function tests and skin-prick tests were externally entered and verified. Range and logic checks were performed to confirm the validity of the data. Association between categorical variables was assessed by the Chi-squared test and comparison of continuous variables by Student's t-test using the Statistical Package for the Social Sciences (SPSS) computer package (Norusis MJ, SPSS Inc 1995, Chicago, IL, USA). All prevalence rates for reported illness from food were estimated using the random sample participants only.

Univariate and multivariate analyses were conducted using the Statistical Analysis System (SAS) computer package (SAS Institute Inc, 1988; Cary, NC, USA). Multivariate models of illness from food and symptoms were fitted using stepwise multiple logistic regression. Univariate and multivariate analyses used participants from both the random and symptomatic samples.

\section{Results}

Table 1 details the response rates and subject characteristics of the random sample and the combined random and symptomatic samples.

Table 1. - Characteristics of subjects and response rates for both random sample alone and combined random and symptomatic samples

\begin{tabular}{|c|c|c|}
\hline & $\begin{array}{l}\text { Random } \\
\text { sample }\end{array}$ & $\begin{array}{l}\text { Random + } \\
\text { symptomatic } \\
\text { sample }\end{array}$ \\
\hline No. completing questionnaire $n$ & 669 & 876 \\
\hline Age* yrs & $34.3(6.81)$ & $34.2(6.83)$ \\
\hline Females \% & 52 & 53 \\
\hline Valid skin-prick tests $n$ & 545 & 745 \\
\hline $\begin{array}{l}\text { Underwent methacholine } \\
\text { challenge } \mathrm{n}(\% \mathrm{BHR} \text { positive })\end{array}$ & $509(28)$ & $675(36)$ \\
\hline Wheeze in past 12 months $\%$ & 35 & 45 \\
\hline Atopic \% & 51 & 56 \\
\hline $\begin{array}{l}\text { "Allergy vaccination" } \\
\text { (immunotherapy) \% }\end{array}$ & 5 & 7 \\
\hline Ever smoked $\%$ & 51 & 51 \\
\hline Current smokers \% & 24 & 25 \\
\hline $\begin{array}{l}\text { Regularly exposed to passive } \\
\text { smoking \% }\end{array}$ & 35 & 36 \\
\hline Body mass index $* \mathrm{~kg} \cdot \mathrm{m}^{-2}$ & $25.2(3.8)$ & $25.4(4.1)$ \\
\hline
\end{tabular}


Table 2. - Food items reported to have caused an illness after eating $(n=128)$

\begin{tabular}{lc}
\hline Item & Responses $\%$ \\
\hline Fruits, fresh/frozen/canned & 14.5 \\
Seafood/shellfish/fish & 11.3 \\
Dairy products, milk/cheese/yoghurt/ice-cream & 10.4 \\
Herbs/spices/condiments/garlic/chilli & 5.4 \\
Monosodium glutamate & 5.0 \\
Alcohol & 5.0 \\
Eggs & 4.1 \\
Fats/oils, butter/margarine/cream/salad dressing & 4.1 \\
Chocolate & 3.6 \\
Vegetables, fresh/frozen/canned & 3.6 \\
Red meat, fresh & 3.6 \\
High fat foods & 3.2 \\
Nuts, including peanut butter/coconut & 3.2 \\
Wheat products, bread/plain cereals & 2.7 \\
Sugar, including golden syrup/jam & 1.8 \\
Restaurant meals/take-away meals & 1.8 \\
Fruits, dried & 1.4 \\
Sauces, including tomato paste/seasonings & 1.4 \\
Tea/coffee & 1.4 \\
Poultry & 1.4 \\
Spicy foods & 1.4 \\
Processed meats, including ham/bacon & 1.4 \\
Other (12 separate items cited) & 8.8
\end{tabular}

\section{Reported illness from food (random sample)}

Twenty five per cent of respondents $(n=167)$ indicated that they had experienced "illness or trouble" caused by eating a particular food or foods. Seventy eight per cent of those reporting an illness $(n=128,19 \%$ of all respondents) nearly always had the same illness or trouble after eating particular food(s). Excluding those who reported nonspecific symptoms, such as lethargy/tiredness, tachycardia or heartburn/indigestion, $17 \%(n=114)$ of all respondents perceived that they had food intolerance or food allergy.

The food items that were reported as causing illness or trouble when eaten are listed in table 2 . Thirty four different items were cited as causing illness from food. Table 3 outlines the types of symptoms that were reported by eating particular foods. Only eight respondents reported that a particular food caused respiratory symptoms alone.

Respondents with current asthma did not report more perceived food intolerance or food allergy than those without asthma $\left(\chi^{2}=0.005, \mathrm{p}=0.94\right)$.
Risk factors for reporting illness from food (random + symptomatic sample)

No statistically significant associations were found between reporting the same illness or trouble after eating food and age, gender, BHR, atopy, asthma status, FEV1, body mass index (BMI), smoking status or allergen immunotherapy.

Univariate analysis showed that respondents who reported respiratory symptoms nearly always after a particular food(s) were more likely to be atopic, BHR positive, have current asthma, have wheezed or to have used inhaled respiratory medications within the past 12 months, have a lower per cent predicted FEV1, weigh more and were less likely to have reported exposure to passive smoking over the past 12 months (table 4). No statistically significant associations were found between food-related respiratory symptoms and age, gender, BMI, active smoking status or allergen immunotherapy. Multivariate analysis confirmed that atopy, use of inhaled respiratory medications in the past 12 months, increasing weight and less exposure to regular passive smoking over the previous 12 months were the only independent predictors for respiratory symptoms following the ingestion of food (table 4). When current asthma was fitted in a multivariate model, and atopy or inhaled respiratory medications were excluded, current asthma was still not significantly associated with foodrelated respiratory symptoms.

Those respondents who reported that respiratory symptoms alone nearly always occurred after a particular food(s), were more likely to be atopic, to have used inhaled respiratory medications in the past 12 months, had a lower percentage predicted FEV1, were taller and weighed more (table 4). Multivariate analysis found that impaired FEV1 was the only independent factor which predicted reporting of respiratory symptoms alone, which nearly always occurred after eating food (table 4).

\section{Discussion}

We found that $17 \%$ of young adults reported that a particular food or foods nearly always caused "illness or trouble" when eaten, presumably due to either food intolerance or food allergy. These results are consistent with other similar international studies which have been conducted in the UK, USA, and the Netherlands which found reported food intolerance prevalence rates of 20, 16

Table 3. - Reported symptoms that occur nearly every time following eating particular food(s) $(n=128)$

\begin{tabular}{|c|c|c|c|}
\hline Symptom type & $\begin{array}{l}\text { Subjects reporting } \\
\text { symptoms } \mathrm{n}\end{array}$ & $\begin{array}{l}\text { Items } \\
\text { cited } \mathrm{n}\end{array}$ & $\begin{array}{l}\text { Most commonly reported food items responsible for symptom } \\
\text { (\% of responses) }\end{array}$ \\
\hline $\begin{array}{l}\text { Gastro-intestinal (nausea, } \\
\text { vomiting, diarrhoea) }\end{array}$ & 58 & 24 & Dairy $(16 \%)$, seafood $(14 \%)$, fresh fruits $(9 \%)$ \\
\hline Urticaria & 31 & 18 & Fresh fruit $(25 \%)$, seafood $(15 \%)$, nuts $(10 \%)$, eggs $(10 \%)$ \\
\hline Severe headache & 22 & 16 & Alcohol (14\%), monosodium glutamate $(14 \%)$ \\
\hline Rhinitis & 18 & 17 & Dairy $(25 \%)$ \\
\hline Respiratory & 17 & 14 & $\begin{array}{l}\text { Fresh fruit }(9 \%) \text {, dried fruit }(9 \%) \text {, dairy }(9 \%) \text {, chocolate }(9 \%) \text {, sauces } \\
(9 \%) \text {, alcohol }(9 \%) \text {, high fat foods }(9 \%) \text {, monosodium glutamate }(9 \%)\end{array}$ \\
\hline Nonspecific & 15 & 13 & Seafood $(20 \%)$ \\
\hline Angio-oedema & 11 & 7 & Fresh fruit $(31 \%)$, seafood $(15 \%)$, nuts $(15 \%)$, alcohol $(15 \%)$ \\
\hline Lethargy/tiredness & 5 & 8 & Dairy $(27 \%)$, sugar $(18 \%)$ \\
\hline Heartburn/indigestion & 4 & 5 & Fresh fruit, dairy, nuts, pastry, fats/oils \\
\hline Tachycardia & 3 & 5 & Fresh vegetables, chocolate, eggs, herbs/spices, monosodium glutamate \\
\hline
\end{tabular}


Table 4. - Crude and adjusted associations between asthma-related and other variables and the reporting of foodrelated illness

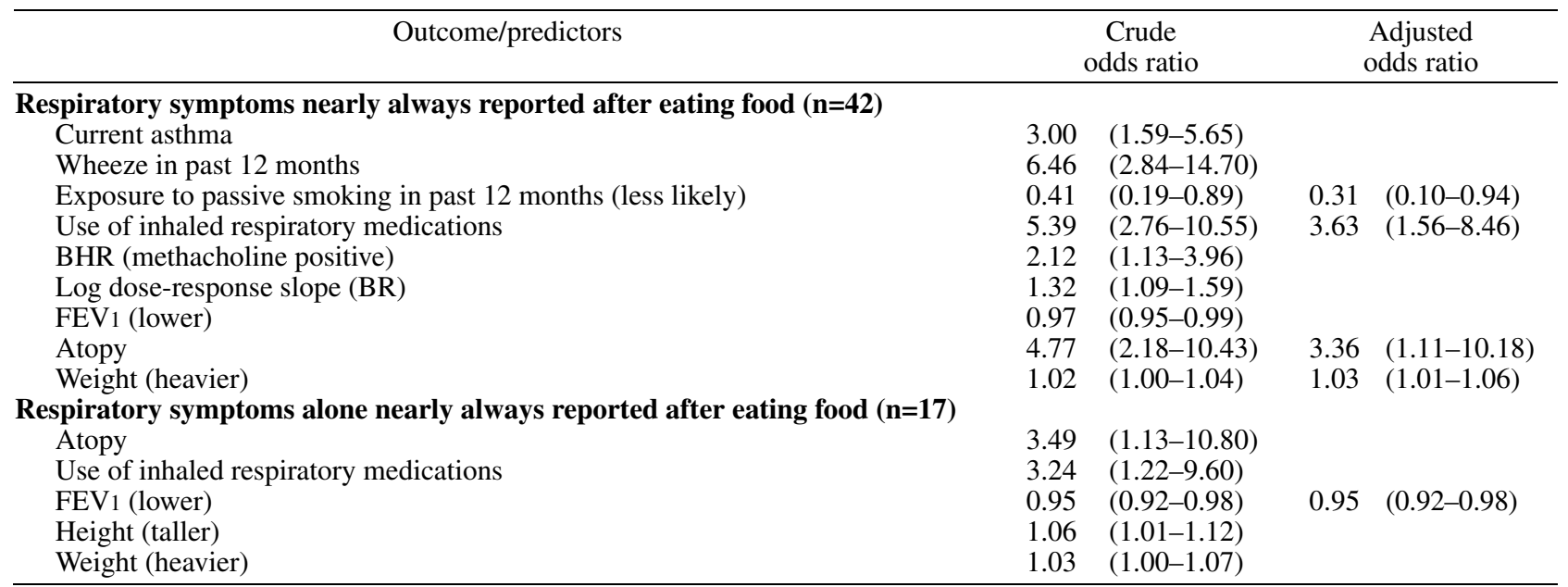

Values in parentheses are 95\% confidence intervals. BHR: bronchial hyperresponsiveness; BR: bronchial responsiveness; FEV1: forced expiratory volume in one second.

and $12 \%$, respectively [20-22]. Whilst the true prevalence of food intolerance remains unknown, double-blind, placebo-controlled food challenge studies suggest that the prevalence of food intolerance is closer to $2 \%$ [23-25]. Obviously, there is a wide gap between the actual prevalence of food intolerance and public perceptions of it. The high level of perception of food intolerance does have significant potential consequences. It has been previously documented in children that unnecessarily restrictive diets can result in nutritional deficiencies and may, in extreme cases, be fatal [26-28]. Public education strategies are, therefore, required to deal explicity with this disparity.

When interpreting the results of this study, account must be taken of several factors that limit the extent to which generalizations can be made about the community, in terms of symptom prevalence. The response rate was poor, with only $42 \%$ of those invited to take part in the random sample completing the questionnaire. We have previously found that the randomly selected subjects who attended the laboratory were significantly more likely than those who were interviewed by telephone to report wheeze or an attack of asthma over the preceding 12 months, thus indicating some volunteer bias [29].

This study used a cross-sectional design and asked whether respondents had "ever" experienced symptoms and was, thus, unable to investigate a temporal relationship between previous symptoms and current asthma status. The associations that were found with reporting of food-related symptoms require further investigation and verification in prospective studies. Causal relationships should not be inferred from these results alone.

Participants with current asthma did not report a higher prevalence of food-related illness in general than those without asthma in this study. These results suggest that dietary manipulations are not unique to the asthma population, but merely reflect general community concern about diet and health.

We did find that atopy was a risk factor for reporting respiratory symptoms following food ingestion and it is well known that atopy is an important risk factor for asthma in young adults [30]. Using inhaled respiratory medications was also found to be an independent risk factor, which provides some evidence that those with respiratory symptoms requiring treatment are more likely to report food intolerance. It is unclear why current asthma (defined as positive BHR and reported wheeze in the past 12 months) alone was not associated with food intolerance, although the numbers of people reporting food intolerance may have been insufficient for a small effect to be detected. Another possible reason could be that the wording of the relevant question did not specifically relate food intake to respiratory symptoms alone. The general wording of the question may have made it difficult to determine whether there was really any difference in perceived food intolerance between people with asthma and those without asthma.

Less exposure to regular passive smoking and obesity were also found to be independent risk factors for reporting respiratory symptoms following food ingestion. These findings may reflect lifestyle or the fact that people with asthma tend to avoid smoky environments and exercise. Further research into this area is required before any conclusions can be made. A larger study population would enable more comprehensive multivariate analyses to be performed, allowing a clearer insight into the possible relationship between asthma and reported food intolerance.

It was interesting that fruits (fresh/frozen/canned) were the most commonly reported food items causing illness. However, double-blind, placebo-controlled studies in adults have not supported fruit being a common cause of food intolerance [20, 23]. Although immunological cross reactivity of plant aeroallergens with fruits is well documented as the "oral allergy syndrome", the clinical relevance of this remains unclear [31]. Future studies should obtain further information by incorporating specific radioallergosorbent tests (RASTs) for commonly reported food allergens.

We found significant limitations in the ECRHS questionnaire for dietary analysis. Quantitative assessment of dietary intake or exposure levels to food additives, can only be obtained using accepted dietary assessment methodology such as dietary recall, quantification of intake or semiquantitative food frequency questionnaires [32, 33]. 
As the questionnaire did not collect this information we were unable to assess any food intake patterns and dietdisease relationships

In conclusion, we found that young adults perceive that food intolerance and allergies are common. Clinicians should be aware of these perceptions and manage them appropriately because of the significant nutritional consequences that may result from dietary restriction. Public education strategies are also required to address this issue. Atopic subjects and those using inhaled respiratory medications may be at greater risk of food-related symptoms. Future studies into possible diet-disease relationships should use appropriate dietary assessment methods to clarify the risk factors. With an adequate instrument an international survey could assess whether international variations in asthma prevalences may be related to dietary differences.

Acknowledgements: The authors wish to acknowledge the assistance of C. Hartley-Sharpe and A. Lanigan with interviewing and testing in the Lung Function Laboratory, and of J. Kutin with data management and analysis.

\section{References}

1. Pearce N, Weiland S, Keil U, et al. Self reported prevalence of asthma symptoms in children in Australia, England, Germany and New Zealand: an international comparison using the ISAAC protocol. Eur Respir $J$ 1993; 6: 1455-1461.

2. Burney PGJ, Luczynska C, Chinn S, Jarvis D. The European Community respiratory health survey. Eur Respir J 1994; 7: 954-960.

3. European Community Respiratory Health Survey. Variations in the prevalence of respiratory symptoms, selfreported asthma attacks, and use of asthma medication in the European Community Respiratory Health Survey (ECRHS). Eur Respir J 1996; 9: 687-695.

4. Warner JO. Food intolerance and asthma. Clin Exp Allergy 1995; 25 (Suppl. 1): 29-30.

5. Hatch GE. Asthma, inhaled oxidants and dietary antioxidants. Am J Clin Nutr 1995; 61 (Suppl. 1): 625S-630S.

6. Landon RA, Young EA. Role of magnesium in regulation of lung function. J Am Diet Assoc 1993; 93: 674-677.

7. Flatt A, Pearce N, Thomson CD, Sears MR, et al. Reduced selenium in asthmatic subjects in New Zealand. Thorax 1990; 45: 95-99.

8. Schwartz J, Weiss ST. The relationship of dietary fish intake to level of pulmonary function in the first National Health and Nutrition Survey (NHANES I). Eur Respir J 1994; 7: 1821-1824.

9. Antonios TFK, MacGregor GA. Deleterious effects of salt intake other than effects on blood pressure. Clin Exp Pharmacol Physiol 1995; 22: 180-184.

10. Woods RK, Weiner J, Abramson M, Thien F, Walters EH. Patients' perceptions of food-induced asthma. Aust NZ J Med 1996; 26: 504-512.

11. Dawson KP, Ford RPK, Mogridge N. Childhood asthma: what do parents add or avoid in their children's diets? NZ Med J 1990; 103: 239-240.

12. Chiaramonte LT, Altman D. Food sensitivity in asthma: perception and reality. J Asthma 1991; 28: 5-8.

13. Griffin T, Jones J, Stevens D, Henry RL. Dietary modifi- cations in children with asthma. Aust J Nutr Diet 1996; 53: 62-64.

14. Metcalfe DD, Sampson HA. Workshop on experimental methodology for clinical studies of adverse reactions to foods and food additives. J Allergy Clin Immunol 1990; 86: 421-442.

15. Bock SA, Aitkens FM. Patterns of food hypersensitivity during sixteen years of double-blind placebo controlled food challenges. J Pediatr 1990; 117: 561-567.

16. Onorato J, Merland N, Terral C, Michel FB, Bousquet J. Placebo controlled double-blind food challenge in asthma. J Allergy Clin Immunol 1986; 78: 1139-1146.

17. Abramson M, Kutin J, Czarny D, Walters EH. The prevalence of asthma and respiratory symptoms among young adults: is it increasing in Australia? J Asthma 1996; 33: 189-196.

18. American Thoracic Society. Standardization of spirometry - 1987 update. Am Rev Respir Dis 1987; 136: 1285-1298.

19. Toelle BG, Peat JK, Salome CM, Mellis CM, Woolcock AJ. Toward a definition of asthma for epidemiology. Am Rev Respir Dis 1992; 146: 633-637.

20. Young E, Stoneham MD, Petruckevitch A, Barton J, Rona R. A population study of food intolerance. Lancet 1994; 343: 1127-1130.

21. Altman DR, Chiaramonte LT. Public perception of food allergy. J Allergy Clin Immunol 1996; 97: 1247-1251.

22. Jansen JJ, Kardinaal AF, Huijbers G, Vlieg-Boerstra BJ, Martens BP, Ockhuizen T. Prevalence of food allergy and intolerance in the Dutch population. J Allergy Clin Iтmиnol 1994; 93: 446-456.

23. Sampson HA, Metcalfe DD. Immediate reactions to foods In: Metcalfe DD, Sampson HA, Simon RA, eds. Food Allergy: Adverse Reactions to Foods and Food Additives. Boston, Blackwell Scientific Publications, 1991; pp. 99112.

24. Nichaman MZ, McPherson RS. Estimating prevalence of adverse reactions to foods: principles and constraints. $J$ Allergy Clin Immunol 1986; 78: 148-154.

25. Anderson JA. The clinical spectrum of food allergy in adults. Clin Exper Allergy 1991; 21 (Suppl. 1): 304-315.

26. Robertson DAF, Ayres RCS, Smith CL, Wright R. Adverse consequences arising from misdiagnosis of food allergy. Br Med J 1988; 297: 719-720.

27. Lloyd-Still JD. Chronic diarrhoea of childhood and the misuse of elimination diets. J Pediatr 1979; 95: 10-13.

28. Davidovitis M, Levy Y, Avramovitz T, Eisenstein B. Calcium-deficiency rickets in a four-year-old boy with milk allergy. J Pediatr 1993; 122: 249-251.

29. Kutin J, Abramson M, Raven J, Lanigan A, Czarny D, Walters EH. Non-responders and volunteers: can't live with them: can't live without them. Am J Respir Crit Care Med 1995; 151 (4,2): A567.

30. Abramson M, Kutin JJ, Raven J, Lanigan A, Czarny D, Walters EH. Risk factors for asthma among young adults in Melbourne, Australia. Respirology 1996; 1(4): 291-297.

31. Bock SA. Oral challenge procedures. In: Metcalfe DD, Sampson HA, Simon RA, eds. Food Allergy: Adverse Reactions to Foods and Food Additives. Boston, Blackwell Scientific Publications, 1991; pp. 81-95.

32. Stamler J. Assessing diets to improve world health: nutritional research on disease causation in populations. Am J Clin Nutr 1994; 59 (Suppl.): 146S-156S.

33. Petersen BJ, Chaisson CF, Douglass JS. Use of foodintake surveys to estimate exposures to nonnutrients. $\mathrm{Am}$ J Clin Nutr 1994; 59 (Suppl.): 240S-243S. 